\title{
Congenital diaphragmatic eventration and hernia sac compared to CDH with true defects: a retrospective cohort study
}

\author{
Kim Heiwegen ${ }^{1}$ - Arno FJ van Heijst ${ }^{2} \cdot$ Horst Daniels-Scharbatke $^{1}$ - Michelle CP van Peperstraten ${ }^{1} \cdot$ Ivo de Blaauw $^{1}$. \\ Sanne MBI Botden ${ }^{1}$
}

Received: 26 July 2019 / Revised: 6 January 2020 / Accepted: 10 January 2020 / Published online: 22 January 2020

(C) The Author(s) 2020

\begin{abstract}
Congenital diaphragmatic eventration (CDE) and congenital diaphragmatic hernia (CDH) with or without hernia sac are three different types of congenital diaphragmatic malformations, which this study evaluates. All surgically treated patients with CDE or Bochdalek type CDH between 2000 and 2016 were included in this retrospective analysis. Demographics, CDH-characteristics, treatment, and clinical outcome were evaluated. In total, 200 patients were included. Patients with an eventration or hernia sac had no significant differences and were compared as patients without a true defect to patients with a true defect. The 1-year survival of patients with a true defect was significantly lower than patients with no true defect $(76 \%$ versus $97 \%, p=0.001)$. CDH with no true defect had significantly better short-term outcomes than $\mathrm{CDH}$ with true defect requiring patch repair. However, at 30 days, they more often required oxygen supplementation $(46 \%$ versus $26 \%, p=0.03)$ and had a higher recurrence rate $(8 \%$ versus $0 \%$, $p=0.006$ ) (three eventration and two hernia sac patients). Conclusion: Patients without a true defect seem to have a more similar clinical outcome than $\mathrm{CDH}$ patients with a true defect, with a better survival. However, the recurrence rate and duration of oxygen supplementation at 30 days are higher than CDH patients with a true defect.
\end{abstract}

\section{What is Known:}

- Congenital diaphragmatic hernia with or without hernia sac and congenital diaphragmatic eventration (incomplete muscularization) are often treated similarly.

- Patients with hernia sac and eventration are thought to have a relatively good outcome, but exact numbers are not described.

What is New:

- Congenital diaphragmatic eventration and patients with hernia sac seem to have a more similar clinical outcome than Bochdalek type CDH with a true defect.

- Patients without a true defect (eventration or hernia sac) have a high recurrence rate.

Keywords Congenital diaphragmatic hernia $\cdot$ Eventration $\cdot$ Hernia sac $\cdot$ Recurrence $\cdot$ Pulmonology

Communicated by Piet Leroy

Kim Heiwegen

Kim.Heiwegen@radboudumc.nl

Arno FJ van Heijst

Arno.vanHeijst@radboudumc.nl

Horst Daniels-Scharbatke

Horst.Daniels-Scharbatke@ radboudumc.nl

Michelle CP van Peperstraten

Michelle.vanPeperstraten@radboudumc.nl
Ivo de Blaauw

Ivo.deBlaauw@radboudumc.nl

Sanne MBI Botden

Sanne.Botden@radboudumc.nl

1 Department of Surgery, Division of Pediatric Surgery, Radboudumc-Amalia Children's Hospital, Route 618, PO box 9101, 6500 Nijmegen, HB, Netherlands

2 Department of Neonatology, Radboudumc-Amalia Children's Hospital, Nijmegen, Netherlands 


\begin{tabular}{|c|c|}
\hline \multicolumn{2}{|l|}{ Abbreviations } \\
\hline $\mathrm{CDE}$ & congenital diaphragmatic eventration \\
\hline $\mathrm{CDH}$ & congenital diaphragmatic hernia \\
\hline $\mathrm{CDH}_{\text {prim }}$ & $\begin{array}{l}\text { congenital diaphragmatic hernia, Bochdal } \\
\text { type, without hernia sac, primary repair }\end{array}$ \\
\hline $\mathrm{CDH}_{\text {patch }}$ & $\begin{array}{l}\text { congenital diaphragmatic hernia, Bochdalek } \\
\text { type, without hernia sac, patch repair }\end{array}$ \\
\hline $\mathrm{CDH}_{\text {notruedefect }}$ & $\begin{array}{l}\text { congenital diaphragmatic hernia with no } \\
\text { true defect, total group (eventration and }\end{array}$ \\
\hline $\mathrm{CDH}_{\text {truedefect }}$ & $\begin{array}{l}\text { congenital diaphragmatic hernia, Bochdalek } \\
\text { type, without hernia sac }\end{array}$ \\
\hline $\mathrm{CMO}$ & extracorporeal membrane oxygenation \\
\hline & neonatal intensive care unit \\
\hline
\end{tabular}

\section{Introduction}

The clinical presentation of a congenital diaphragmatic hernia $(\mathrm{CDH})$ can be variable, and the prognosis depends on multiple factors, with survival rates ranging from 70 to $80 \%[1,2]$. The most common type of a diaphragmatic defect is a posterolateral defect also known as Bochdalek hernia, which accounts for about $85 \%$ of the cases [3]. Bochdalek hernias occur due to an abnormal pleura-peritoneal fold development, where normally these folds fuse between the 5 th and 7 th week of gestation [4]. In this type of $\mathrm{CDH}$, organs may herniate into the thorax because of the incomplete diaphragm. Congenital diaphragmatic eventration (CDE) is clinically seen and often treated as another subtype of $\mathrm{CDH}$, although in the worldwide used CDH study group (CDHSG) scoring system, a specific classification for eventration, does not exist $[3,5,6]$. In CDE, there is incomplete muscularization of the (hemi)diaphragm, which results in a weakened muscularized dysfunctional diaphragm causing protrusion of abdominal contents into the thoracic cavity [4]. Clinical manifestations are diverse, varying from asymptomatic to life-threatening respiratory distress. Overall, it is thought to have a relatively good outcome, but exact numbers are not described [7], because most studies do not specify this subtype as a specific entity [2, 8-12].

$\mathrm{CDH}$ type Bochdalek patients can either have a true defect ("classic") or a hernia sac, which has been described in 14 $20 \%$ of cases. The latter type is often considered as a common variation of the "classic" $\mathrm{CDH}[3,13-15]$. In patients with a hernia sac, a non-muscularized pleuroperitoneal sac covers the herniated organs in the thorax $[13,14]$. As however no explanation for the development of a hernia sac has yet been found, the question raises whether these patients with no "classic" true defect are more similar to the other patients with no true defect: CDE patients. Although the three different types described (CDH with a defect, $\mathrm{CDH}$ with a hernia sac and congenital diaphragmatic eventration) seem to be part of one spectrum, they may have been caused by different embryological events. The aim of this study is to evaluate whether there is a difference in clinical outcome between Bochdalek $\mathrm{CDH}$ with a true defect and patients without a true defect (hernia sac and eventration patients). A subanalysis will be performed to evaluate whether the presence of a hernia sac has more comparable clinical outcomes to CDE rather than Bochdalek type $\mathrm{CDH}$ with a true defect.

\section{Methods}

\section{Inclusion and exclusion}

All surgically repaired patients with a $\mathrm{CDH}$ diagnosed between January 2000 and December 2016 in a high volume center (Radboudumc-Amalia Children's hospital, Nijmegen, the Netherlands) were included in this study. Exclusion criteria were incomplete data (no information on type of defect and presence of hernia sac), Morgagni hernias, and Pentalogy of Cantrell (Fig. 1). Patients that died before surgical repair were excluded, because no information on the type of defect was available. For long-term pulmonary outcomes at 30 days or at discharge, patients who died before this date were excluded in the analyses.

\section{Subgroups}

Patients with a recorded $\mathrm{CDE}$ were compared to the patients with a Bochdalek type $\mathrm{CDH}$ with a true defect $\left(\mathrm{CDH}_{\text {truedefect }}\right)$ and those with a hernia sac $\left(\mathrm{CDH}_{\text {herniasac }}\right)$, and if comparable, they were combined to form one group $\left(\mathrm{CDH}_{\text {notruedefect }}\right)$. The $\mathrm{CDH}_{\text {truedefect }}$ group was divided in primary closure $\left(\mathrm{CDH}_{\text {prim }}\right)$ or patch closure $\left(\mathrm{CDH}_{\text {patch }}\right)$, as a surrogate for the defect size.

\section{Protocol}

Patient records were evaluated retrospectively for multiple parameters, such as demographics, perinatal parameters, and $\mathrm{CDH}$ characteristics. Prenatal diagnosis was based on either the standard 20-weeks' gestation obstetric ultrasound or a prenatal ultrasound at another time point. Cardiac malformations were classified as major when hemodynamic effects occurred, as stated by the CDH study group (CDHSG) [16]. Because the defect size according to the CDHSG scoring system was introduced during the studied period and these data were missing in the majority of cases, the use of a patch respectively primary repair was used as a surrogate for the defect size [6]. After 2010, the patient was managed according to the standard of care for $\mathrm{CDH}$ patients at present time, supplemented by standard protocol proposed by the $\mathrm{CDH}$ Euroconsortium consensus paper [17]. Pulmonary hypertension was scored as either diagnosed on ultrasound or medication required. ECMO was offered to patients with severe respiratory failure and 
Fig. 1 Exclusion and division of subgroups of the total group of $\mathrm{CDH}$ patients

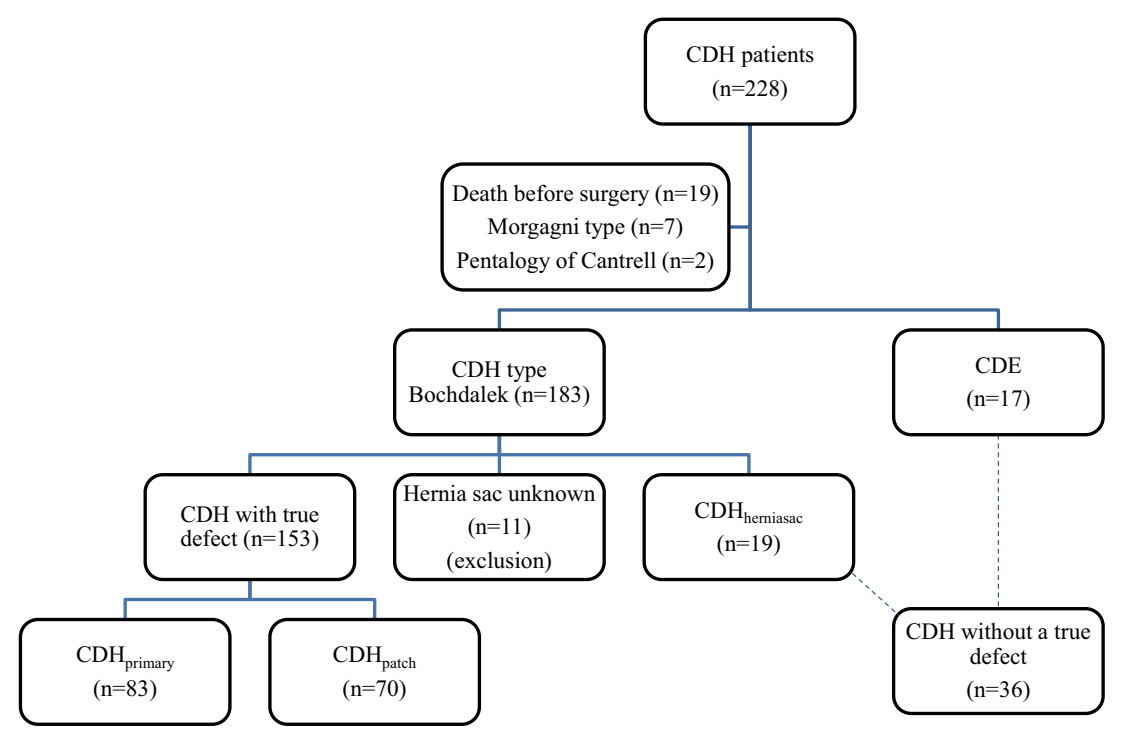

pulmonary hypertension when standard therapy failed according to the $\mathrm{CDH}$ Euroconsortium consensus [17]. All patch repairs were performed using PTFE-material (Goretex®). In the occurrence of a hernia sac, it was standard to excise the sac, or in some cases, it was used as an onlay tissueflap on the defect when it was closed by a patch. CDE was preferably repaired using plication of the diaphragm, although additional patch repair was used on indication. During follow-up, patients were evaluated on possible symptoms of recurrences and checked with standard two-plain X-rays postoperative, before discharge, during the follow-up, and on indication. Recurrences were diagnosed on two-plain x-rays of the thorax, in which a significant bulging or high position of the diaphragm was considered a recurrence.

\section{Outcomes}

Primary outcomes of this study were survival and recurrence rate in the first year. Secondary outcomes were medical and surgical treatment (such as ECMO, primary or patch repair) and perioperative surgical complications such as hemorrhage, chylothorax, and recurrence rate during follow-up. Other outcome parameters were the need for oxygen supplementation, CPAP, or intubation at 30 days of life (DOL) and need of oxygen suppletion at time of discharge to home or another hospital. Mechanical ventilation or oxygen supplementation was used as a surrogate for lung development or short-term pulmonary status.

\section{Statistics}

Values are expressed as means with standard deviations (SD), median with range, or in absolute numbers with percentages, when appropriate. Differences between patient groups were compared using the independent Student's t test or Mann-
Whitney $\mathrm{U}$ test for continuous variables and the chi-square or Fisher's exact test for categorical variables. A $p$ value of $<0.05$ was considered statistically significant. Data management and analyses were performed using IBM SPSS Statistics 22 .

\section{Results}

In the study period, 228 patients were admitted for $\mathrm{CDH}$ in this tertiary center. Patients before and after 2010 (after the $\mathrm{CDH}$ Euroconsortium paper, as stated in the methods [16]) were compared on demographics, treatment, and outcomes. Comparison showed that there were no significant differences between these parameters during these two periods. The inclusion of the patients and division in the subgroups are demonstrated in Fig. 1, leaving 200 patients eligible for this study. They had a median follow-up of 11 years (range: 1-18). Of the total group, $77 \%$ had a $\mathrm{CDH}$ Bochdalek with a true defect $\left(\mathrm{CDH}_{\text {truedefect }}\right), 10 \%$ had a $\mathrm{CDH}$ Bochdalek with a hernia sac $\left(\mathrm{CDH}_{\text {herniasac }}\right)$, and $9 \%$ was diagnosed with an eventration.

\section{Demographics and treatment of the three groups: Bochdalek type CDH with true defect, CDE, and hernia sac}

Demographic characteristics of the three groups, $\mathrm{CDH}_{\text {truedefect }}$, $\mathrm{CDE}$, and $\mathrm{CDH}_{\text {herniasac }}$ patients, were described (Table 1). Only side of defect was different between the three groups, with a higher rate of right sided defects in the hernia sac and eventration cohort $(p=0.008)$. Patients with eventration and hernia sac had a higher rate of birth defects (31\% and 26\%) than patients with a true defect $(11 \%, p=0.02)$. Other birth defects reported were dysmorphic characteristics in three CDE patients versus two $\mathrm{CDH}_{\text {herniasac }}$ patients, vertebral anomalies in two $\mathrm{CDH}_{\text {herniasac }}$ patients and urogenital abnormalities 
Table 1 Demographics and perinatal characteristics of $\mathrm{CDH}$ with true defect, $\mathrm{CDE}$, and $\mathrm{CDH}_{\text {hernia sac }}$

\begin{tabular}{|c|c|c|c|c|c|}
\hline & $\operatorname{CDE}(n=17)$ & $\mathrm{CDH}_{\text {herniasac }}(n=19)$ & $\mathrm{CDH}_{\text {truedefect }}(n=153)$ & $P$ value & $P$ value $\left(\mathrm{CDE} / \mathrm{CDH}_{\text {herniasac }}\right)$ \\
\hline Gender - female & $9(52.9)$ & $10(52.6)$ & $52(34)$ & 0.11 & 0.99 \\
\hline Gestational age in weeks ${ }^{1}$, median (range) & $38.1(31.3-41.7)$ & $38.3(30.1-42.7)$ & $38.3(27.7-42.3)$ & 0.85 & 0.91 \\
\hline $\begin{array}{l}\text { Birth weight in grams }{ }^{1} \text {, } \\
\text { Mean (SD) }\end{array}$ & $2793(817)$ & $2997(859)$ & $3004(609)$ & 0.55 & 0.52 \\
\hline Liver up & $9(52.9)$ & $9(47.4)$ & $46(30)$ & 0.06 & 0.74 \\
\hline \multicolumn{6}{|l|}{ Apgar score ${ }^{3}$, median (range) } \\
\hline $1 \mathrm{~min}$ & $8(1-10)$ & $8(3-9)$ & $6(0-9)$ & 0.13 & 0.87 \\
\hline $5 \min$ & $9(3-10)$ & $9(7-10)$ & $8(1-10)$ & 0.06 & 0.51 \\
\hline Side hernia & & & & 0.008 & 0.28 \\
\hline Left & $10(58.8)$ & $14(73.7)$ & $131(85.6)$ & & \\
\hline Right & $5(29.4)$ & $5(26.3)$ & $20(13.1)$ & & \\
\hline Bilateral & $2(11.8)$ & $0(0)$ & $2(1.3)$ & & \\
\hline
\end{tabular}

Missing: ${ }^{1} 4,{ }^{3} 5$

$C D E$ congenital diaphragmatic eventration; $C D H_{\text {hernia sac }}$ congenital diaphragmatic hernia, Bochdalek type, with hernia sac; $C D H$ congenital diaphragmatic hernia

(such as hydronephrosis) in two $\mathrm{CDE}$ and two $\mathrm{CDH}_{\text {herniasac, }}$ and a hypospadia in two CDE patients.

\section{Outcomes of the three groups: Bochdalek type CDH with true defect, CDE and hernia sac}

$\mathrm{CDE}$ and $\mathrm{CDH}_{\text {herniasac }}$ patients all survived the first 30 days, compared to $82 \%$ of the patients with a true defect $(p=0.03)$. This higher rate of survival was also significant after 1 year (Table 2). The recurrence rate after 30 days was higher in the

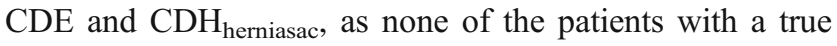
defect developed a recurrence $(p<0.001)$. This was also the case after 1 year (however not significant, $p=0.10$ ) (Table 2). Respiratory support after 30 days was $53 \%$ for CDE, $33 \%$ for $\mathrm{CDH}_{\text {herniasac, }}$ and $26 \%$ for $\mathrm{CDH}$ patients with true defect $(p=$ $0.01)$. At discharge, this was $20 \%$ versus $17 \%$ versus $4 \%$, respectively $(p=0.02)$. Oxygen suppletion was higher after 30 days in patients with eventration (53\%) and hernia sac (39\%) compared to patients with true defects $(26 \%)$, however not significant $(p=0.06)$. This was similar at discharge $(27 \%$ versus $22 \%$ versus $10 \%, p=0.10)$.

\section{CDH patients with no true defect: hernia sac versus eventration patients}

Patients without a true defect (eventration and hernia sac) were compared to each other, which show that there are no statistical significant differences in demographics at all (Table 1). Moreover, there were no differences in treatment or short-term outcomes (Table 2). Use of ECMO was not significantly different and neither was total ECMO run time $\left(\mathrm{CDH}_{\text {truedefect }}\right.$ median 8 (range $\left.1-20\right), \mathrm{CDE}$ patients 11 days (range 9-13), and 6 days (range 4-8) in $\mathrm{CDH}_{\text {herniasac patients) }}$ $(p=0.18)$. Based on our clinical hypothesis, $\operatorname{CDE}(n=17)$ and $\mathrm{CDH}_{\text {herniasac }}(n=19)$ patients were pooled as one (clinical) entity so these patients with no "true" defect $\left(\mathrm{CDH}_{\text {notruedefect }}\right.$, $n=36$ ), meaning no direct adjacency between thorax and abdomen could be compared to the 153 Bochdalek hernia patients with a true defect $\left(\mathrm{CDH}_{\text {truedefect }}\right)$.

\section{CDH without a true defect versus CDH with a true defect}

In Table 3 , the combined group $\left(\mathrm{CDH}_{\text {notruedefect }}\right)$ is compared to $\mathrm{CDH}$ type Bochdalek with a true defect $\left(\mathrm{CDH}_{\text {truedefect }}\right)$. This table shows that the patients in the $\mathrm{CDH}_{\text {notruedefect }}$ group were more often female ( $53 \%$ versus $34 \%, p=0.04$ ) and had higher Apgar scores. They were more often diagnosed with bilateral and right-sided hernias and liver up, which was diagnosed on prenatal ultrasound or perioperatively. The patients had no significant difference in rate of prenatal diagnosis (60\% versus $58 \%, p=1.00)$. As Table 3 also shows, other birth defects besides the diaphragmatic anomaly were more

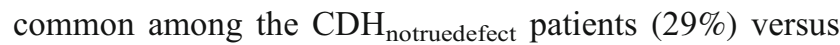
$\mathrm{CDH}_{\text {truedefect }}$ patients $(11 \%)(p=0.01)$.

Although there was no significant difference in presence of pulmonary hypertension between $\mathrm{CDH}_{\text {notruedefect }}$ and $\mathrm{CDH}_{\text {truedefect }}$ patients, ECMO was used more frequently in $\mathrm{CDH}_{\text {truedefect }}$ patients (Table 4). As this table also shows, survival on DOL 30 and after 1 year was significantly better for $\mathrm{CDH}_{\text {notruedefect }}$ (only one eventration patient deceased). When focusing on the surgical treatment, the abdominal fascia of $\mathrm{CDH}_{\text {notruedefect }}$ patients was mainly closed primarily (94\%), compared to $72 \%$ of $\mathrm{CDH}_{\text {truedefect }}$ patients $(p=0.02)$. Recurrences of 
Table 2 Treatment and outcomes of $\mathrm{CDH}$ with true defect, $\mathrm{CDE}$, and $\mathrm{CDH}_{\text {hernia sac }}$

\begin{tabular}{|c|c|c|c|c|c|}
\hline & $\operatorname{CDE}(n=17)$ & $\mathrm{CDH}_{\text {herniasac }}(\mathrm{n}=19)$ & $\mathrm{CDH}_{\text {truedefect }}(n=153)$ & $P$ value & $\mathrm{P}$ value $\left(\mathrm{CDE} / \mathrm{CDH}_{\text {herniasac }}\right)$ \\
\hline \multicolumn{6}{|l|}{ Treatment } \\
\hline \multicolumn{6}{|l|}{ Medical } \\
\hline Pulmonary hypertension ${ }^{1}$ & $7(43.8)$ & $7(41.2)$ & $75(56)$ & 0.37 & 0.88 \\
\hline Use of inhaled nitric oxide ${ }^{2}$ & $3(20)$ & $6(31.6)$ & $67(45.3)$ & 0.11 & 0.70 \\
\hline ECMO & $3(17.6)$ & $2(10.5)$ & $59(38.6)$ & 0.02 & 0.65 \\
\hline \multicolumn{6}{|l|}{ Surgical } \\
\hline Method of repair & & & & 0.02 & 0.65 \\
\hline Primary & $14(82.4)$ & $17(89.5)$ & $83(54.2)$ & & \\
\hline Patch & $3(19)$ & $2(10.5)$ & $70(45.8)$ & & \\
\hline Non-closure of fascia ${ }^{1}$ & $1(6.7)$ & $1(5.6)$ & $41(27.7)$ & 0.03 & 1.00 \\
\hline \multicolumn{6}{|l|}{ Outcome } \\
\hline \multicolumn{6}{|l|}{ Survival } \\
\hline 30-days & $17(100)$ & $19(100)$ & $126(82.4)$ & 0.03 & - \\
\hline 1-year & $16(94.1)$ & $19(100)$ & $116(75.8)$ & 0.01 & 0.47 \\
\hline Surgical complications & $6(35.3)$ & $5(26)$ & $53(34.9)$ & 0.76 & 0.72 \\
\hline Hemorrhage $^{3}$ & $2(12.5)$ & $1(5.3)$ & $16(84.2)$ & 0.73 & 0.58 \\
\hline Chylothorax ${ }^{3}$ & $1(6.3)$ & $2(10.5)$ & $30(19.7)$ & 0.28 & 1.00 \\
\hline \multicolumn{6}{|l|}{ Recurrence of hernia } \\
\hline 30 days & $1(5.9)$ & $2(10.5)$ & $0(0)$ & $<0.001$ & 1.00 \\
\hline 1 year $^{3}$ & $2(11.8)$ & $3(16.7)$ & $7(4.7)$ & 0.10 & 1.00 \\
\hline
\end{tabular}

Missing: ${ }^{1} 3,{ }^{2} 2,{ }^{3} 1$

$C D E$ congenital diaphragmatic eventration; $C D H_{\text {herniasac }}$ congenital diaphragmatic hernia, Bochdalek type, with hernia sac; $C D H_{\text {truefefect }}$ congenital diaphragmatic hernia, Bochdalek group, without hernia sac; ECMO extracorporeal membrane oxygenation; NICU neonatal intensive care unit

the diaphragmatic defect or eventration occurred more often and earlier in $\mathrm{CDH}_{\text {notruedefect, }}$ in which $8 \%$ was diagnosed with a recurrence within 30 days (one eventration and two hernia sac) compared to $0 \%$ in $\mathrm{CDH}_{\text {truedefect }}(p=0.006)$. This difference remained significant after 1 year (14\% versus $5 \%, p=0.05$, Table 4). Not all of these recurrences required surgical repair, because some patients did not show any symptoms.

When evaluating pulmonary outcome, respiratory ventilation at day 30 was needed in $42 \%$ of $\mathrm{CDH}_{\text {notruedefect }}$ compared to $20 \%$ in $\mathrm{CDH}_{\text {truedefect }}(p=0.009)$. At discharge from our tertiary referral center, there was a significantly higher need for respiratory support for $\mathrm{CDH}_{\text {notruedefect }}$ compared to $\mathrm{CDH}_{\text {truedefect }}(18 \%$ versus $4 \%, p=0.01)$. When correcting for ECMO patients only $\left(\mathrm{CDH}_{\text {notruedefect }}, n=5\right.$, and $\left.\mathrm{CDH}_{\text {truedefect, }}, n=59\right)$, this was $100 \%$ versus $47 \%(\mathrm{p}=0.05)$, respectively, at 30 days and $40 \%$ versus $8 \%$ at discharge $(p=$ 0.12). In $32 \%$ of the non-ECMO patients of the $\mathrm{CDH}_{\text {notruedefect }}$ group, respiratory ventilation was required at day 30 versus $11 \%$ of the non-ECMO patients in the $\mathrm{CDH}_{\text {truedefect }}(\mathrm{p}=0.01)$ and $14 \%$ versus $3 \%$ at discharge $(p=0.04)$. Oxygen supplementation was needed more often in the group of $\mathrm{CDH}_{\text {notruedefect }}$ patients at 30 days $(46 \%$ versus $26 \%, p=$ 0.03 ). At discharge, the difference was $24 \%$ versus $10 \%$, but this was not statistically significant $(p=0.07)$.

\section{CDH without a true defect versus $\mathrm{CDH}$ patients with a true defect divided on type of repair (primary versus patch)}

Table 5 compares the $\mathrm{CDH}_{\text {notruedefect }}$ patients with $\mathrm{CDH}$ patients with a true defect divided on the type of repair, as a surrogate for the defect size as previously explained (see methods). Primary repaired patients with true defects are abbreviated as $\mathrm{CDH}_{\text {prim }}(n=83)$ and patch repaired patients as $\mathrm{CDH}_{\text {patch }}(n=70)$. As Table 5 shows, there were no significant differences between $\mathrm{CDH}_{\text {notruedefect }}$ and $\mathrm{CDH}_{\text {prim }}$ patients regarding medical and surgical treatment. When the $\mathrm{CDH}_{\text {notruedefect }}$ group was compared to the $\mathrm{CDH}_{\text {patch }}$ group (considered the largest defects), $\mathrm{CDH}_{\text {notruedefect }}$ patients required less inhaled nitric oxide and were treated less often with ECMO (Table 5).

When looking at outcomes, the survival rate of the $\mathrm{CDH}_{\text {notruedefect }}$ patients was comparable to $\mathrm{CDH}_{\text {prim }}(p=$ $1.00)$ and significantly better than $\mathrm{CDH}_{\text {patch }}(p<0.001)$. However, the recurrence rate after 30 days was significantly higher for $\mathrm{CDH}_{\text {notruedefect }}$ compared to both the primary and patch repaired patients. After 1 year, the recurrence rate in the $\mathrm{CDH}_{\text {notruedefect }}$ patients was significantly higher compared to the $\mathrm{CDH}_{\text {prim }}$ patients $(14 \%$ versus $1 \%, p=0.009)$ and 
Table 3 Demographics and perinatal characteristics of $\mathrm{CDH}$ patients with and without a true defect

\begin{tabular}{|c|c|c|c|}
\hline & $\mathrm{CDH}_{\text {notruedefect }}(n=36)$ & $\mathrm{CDH}_{\text {truedefect }}(n=153)$ & $P$ value \\
\hline Gender - female & $19(52.8)$ & $52(34)$ & 0.04 \\
\hline Gestational age in weeks ${ }^{1}$, median (range) & $38.3(30.1-42.7)$ & $38.3(27.7-42.3)$ & 0.64 \\
\hline Birth weight in grams ${ }^{2}$, mean (SD) & $2911(834)$ & $3004(609)$ & 0.48 \\
\hline Liver up $^{4}$ & $18(50)$ & $46(30)$ & 0.02 \\
\hline \multicolumn{4}{|l|}{ Apgar score ${ }^{6}$, median (range) } \\
\hline $1 \mathrm{~min}$ & $8(1-10)$ & $6(0-9)$ & 0.05 \\
\hline $5 \min$ & $9(3-10)$ & $8(1-10)$ & 0.02 \\
\hline Side hernia & & & 0.02 \\
\hline Left & $24(66.7)$ & $131(85.6)$ & \\
\hline Right & $10(27.8)$ & $20(13.1)$ & \\
\hline Bilateral & $2(5.6)$ & $2(1.3)$ & \\
\hline Major cardiac malformations $^{7}$ & $0(0)$ & $3(2)$ & 1.00 \\
\hline Chromosomal anomalies $^{8}$ & $4(11.4)$ & $9(6)$ & 0.28 \\
\hline Other birth defects ${ }^{7}$ & $10(28.6)$ & $16(10.5)$ & 0.01 \\
\hline
\end{tabular}

Missing: ${ }^{1} 27,{ }^{2} 23,{ }^{3} 13,{ }^{4} 1,{ }^{5} 8,{ }^{6} 33,{ }^{7} 2,{ }^{8} 5$

$C D H_{\text {notruedefect }}$ eventration and hernia sac patients; $C D H_{\text {truefefect }}$ congenital diaphragmatic hernia, Bochdalek group, without hernia sac; $C D H$ congenital diaphragmatic hernia

comparable to $\mathrm{CDH}_{\text {patch }}$ patients $(p=0.51)$. Pulmonary state at 30 days was worse for the $\mathrm{CDH}_{\text {notruedefect }}$ group when compared to the primary repaired patients (Table 5), which was also true for the primarily repaired patients specifically. After 30 days, the primary repaired patients without a true defect required oxygen in $39 \%$ versus $8 \%$ of the primary repaired patients with a true defect $(\mathrm{p}<0.001)$, and for mechanical ventilator support, this was $36 \%$ versus $7 \%(p<0.001)$. At discharge, this difference for primary repaired patients of $\mathrm{CDH}_{\text {notruedefect }}$ versus $\mathrm{CDH}_{\text {truedefect }}$ was for oxygen supplementation $21 \%$ versus $4 \%(p=0.01)$ and mechanical ventilator support $18 \%$ versus $0 \%(p=0.001)$.

Table 4 Treatment and surgical outcomes of $\mathrm{CDH}$ patients with and without a true defect

\begin{tabular}{|c|c|c|c|}
\hline & $\mathrm{CDE}_{\text {notruedefect }}(n=36)$ & $\mathrm{CDH}_{\text {truedefect }}(n=153)$ & $P$ value \\
\hline \multicolumn{4}{|l|}{ Treatment } \\
\hline Pulmonary hypertension ${ }^{1}$ & $14(42.4)$ & $75(56)$ & 0.16 \\
\hline Use of inhaled nitric oxide ${ }^{2}$ & $9(26.5)$ & $67(45.3)$ & 0.04 \\
\hline ECMO & $5(13.9)$ & $59(38.6)$ & 0.005 \\
\hline Non-closure of fascia ${ }^{3}$ & $2(6.1)$ & $41(27.7)$ & 0.08 \\
\hline Abdominal patch & $1(2.8)$ & $27(17.6)$ & 0.02 \\
\hline \multicolumn{4}{|l|}{ Outcome } \\
\hline \multicolumn{4}{|l|}{ Survival } \\
\hline 30-days & $36(100)$ & $126(82.4)$ & 0.002 \\
\hline 1 -year & $35(97.2)$ & $116(75.8)$ & 0.006 \\
\hline Surgical complications ${ }^{4}$ & $11(30.6)$ & $53(34.9)$ & 0.62 \\
\hline Hemorrhage $^{5}$ & $3(8.6)$ & $16(10.5)$ & 1.00 \\
\hline Chylothorax ${ }^{5}$ & $3(8.6)$ & $30(19.7)$ & 0.12 \\
\hline \multicolumn{4}{|l|}{ Recurrence of hernia } \\
\hline 30 days & $3(8.3)$ & $0(0)$ & 0.006 \\
\hline 1 year $^{6}$ & $5(14.3)$ & $7(4.7)$ & 0.05 \\
\hline
\end{tabular}

Missing: ${ }^{1} 22,{ }^{2} 7,{ }^{3} 8,{ }^{4} 1,{ }^{5} 2,{ }^{6} 6$,

$C D H_{\text {notruedefect }}$ eventration and hernia sac patients; $C D H_{\text {truefefect }}$ congenital diaphragmatic hernia, Bochdalek group, without hernia sac; $E C M O$ extracorporeal membrane oxygenation; NICU neonatal intensive care unit 
Table 5 Treatment and outcomes of $\mathrm{CDH}_{\text {notruefect }}$ versus $\mathrm{CDH}_{\mathrm{Bprim}}$ and $\mathrm{CDH}_{\text {notruedefect }}$ versus $\mathrm{CDH}_{\text {patch }}$

\begin{tabular}{|c|c|c|c|c|c|}
\hline & $\mathrm{CDH}_{\text {notruedefect }}(n=36)$ & $\mathrm{CDH}_{\text {prim }}(n=83)$ & $P$ value & $\mathrm{CDH}_{\text {patch }}(\mathrm{n}=70)$ & $P$ value \\
\hline \multicolumn{6}{|l|}{ Treatment } \\
\hline Pulmonary hypertension & $14(42.2)^{1}$ & $24(32.4)^{2}$ & 0.32 & $51(85)^{3}$ & $<0.001$ \\
\hline Use of inhaled nitric oxide & $9(26.5)^{4}$ & $21(26.3)^{1}$ & 0.98 & $46(68)^{4}$ & $<0.001$ \\
\hline ECMO & $5(13.9)$ & $12(14.5)$ & 0.94 & $47(67)$ & $<0.001$ \\
\hline Non-closure of fascia & $2\left(6.1^{1}\right.$ & $10(12.3)^{4}$ & 0.50 & $31(46)^{1}$ & $<0.001$ \\
\hline Abdominal patch & $1(2.8)$ & $3(3.6)$ & 1.00 & $24(34)$ & $<0.001$ \\
\hline \multicolumn{6}{|l|}{ Outcome } \\
\hline \multicolumn{6}{|l|}{ Survival } \\
\hline 1-year & $35(97.2)$ & $79(95.2)$ & 1.00 & $37(52.9)$ & $<0.001$ \\
\hline Surgical complications & $11(30.6)$ & $17(21)^{5}$ & 0.34 & $37(52.9)$ & 0.03 \\
\hline Hemorrhage & $3(8.6)^{5}$ & $3(3.7)^{5}$ & 0.36 & $13(18.6)$ & 0.18 \\
\hline Chylothorax & $3(8.6)^{5}$ & $10(12.2)^{5}$ & 0.75 & $20(28.6)$ & 0.02 \\
\hline \multicolumn{6}{|l|}{ Recurrence of hernia } \\
\hline 30 days & $3(8.3)$ & $0(0)$ & 0.03 & $0(0)$ & 0.04 \\
\hline 1 year & $5(14.3)^{5}$ & $1(1.2)^{5}$ & 0.009 & $6(9.1)^{6}$ & 0.51 \\
\hline \multicolumn{6}{|l|}{ Pulmonary state 30 days } \\
\hline $\mathrm{O}_{2}$ supplement & $15(45.5)^{1}$ & $6(8)^{7}$ & $<0.001$ & $24(60)^{8}$ & 0.22 \\
\hline Mechanical ventilator support & $14(42.4)^{1}$ & $5(6.7)^{7}$ & $<0.001$ & $18(45)^{8}$ & 1.00 \\
\hline \multicolumn{6}{|l|}{ Pulmonary state discharge } \\
\hline $\mathrm{O}_{2}$ supplement & $8(24.2)^{1}$ & $4(5)^{7}$ & 0.01 & $8(24.2)^{9}$ & 1.00 \\
\hline Mechanical ventilator support & $6(18.2)^{1}$ & $0(0)^{7}$ & 0.01 & $4(12.1)^{9}$ & 0.73 \\
\hline
\end{tabular}

Missing: ${ }^{1} 3,{ }^{2} 9,{ }^{3} 10,{ }^{4} 2,{ }^{5} 1,{ }^{6} 4,{ }^{7} 8,{ }^{8} 30,{ }^{9} 37$

$C D H_{\text {notruedefect }}$ eventration and hernia sac patients; $C D H_{\text {prim }}$ congenital diaphragmatic hernia, Bochdalek group, without hernia sac, primary repair; $C D H_{\text {patch }}$ congenital diaphragmatic hernia, Bochdalek group, without hernia sac, patch repair; ECMO extracorporeal membrane oxygenation; NICU neonatal intensive care unit

\section{Discussion}

This study suggests that $\mathrm{CDE}$ and a Bochdalek type $\mathrm{CDH}$ with hernia sac could have a more comparable clinical characteristics and surgical or short-term pulmonary outcome than patients with a true defect. This could be explained if the hernia sac is considered as an early form of an eventration. Both an eventration and a hernia sac then occur later in the embryology than the complete true defect in the diaphragm [3, $4,15,18]$. The pleura-peritoneal fold has been closed in both scenarios, either just as a weak hernia sac or with little muscularization in case of an eventration, and may have been caused by different embryological events.

Patients with eventration have a significant better survival than the Bochdalek type $\mathrm{CDH}$ with true defect, which has been previously postulated as well [7, 19-22]. This was also stated for CDH patients with a hernia sac [13, 14, 23]. Despite the better survival rates, the two major findings of this study were the clinically relevant high recurrence rate $(14 \%)$ and significantly longer need of respiratory support in patients with an eventration or with a hernia sac compared to (surviving) Bochdalek type $\mathrm{CDH}$ patients with a true defect.
The recurrence rate of $\mathrm{CDH}_{\text {notruedefect }}$ within 1 year was higher than in previous statements, where no recurrences in CDE were reported [7, 19-22]. Then again, the total number of recurrences found in the Bochdalek type $\mathrm{CDH}$ in this cohort $(5 \%)$ is relatively low in comparison to other studies, and the sample sizes of both eventration and hernia sac patients are relatively small $[8,24]$. Previous studies suggested that the severity or defect size of $\mathrm{CDH}$ would be a prognostic value for recurrence rates [24-27], but these cohorts were not adjusted for $\mathrm{CDE}$ and $\mathrm{CDH}$ with hernia sacs. The current study shows that during follow-up of the surviving patients, patients with no true defects have a higher recurrence rate than patients with a true defect. Recurrence rates of $\mathrm{CDH}_{\text {notruedefect }}$ even remain higher than Bochdalek patients with a patch, being a surrogate for large defect sizes in classic $\mathrm{CDH}$. The higher recurrence rate might be explained by the fact that the use of a diaphragm patch for repair in patients with eventration or hernia sac is low, suggesting an underestimation of the strength of the repair. The native diaphragm may have been too weak for a reliable primary closure. The non- or partially muscularized tissue is probably not as strong as normal diaphragm and stretches more easily in the long run, causing more recurrences or new eventration. A 
lower threshold to use of patch closure in patients and resection of the hernia sac or part of the eventration may prevent the recurrences in both $\mathrm{CDH}$ patients with hernia sac or eventration of the diaphragm. However, due to the retrospective nature of these studies, confounding for the manner of hernia sac repair was not possible, a question for which prospective trial would possibly be required.

Another remarkable finding was that the patients with no true defect had a higher need for respiratory support, oxygen supplementation, both at 30 days of life and at time of discharge. For the groups separately, this clinically relevant difference was similar at discharge, however, not significant probably due to the small number of patients in the hernia sac and eventration group. These patients in this study initially had a better outcome but improved clinically less extensive than expected at 30 days and at discharge or even deteriorated. Because the numbers of pulmonary hypertension, treatment with inhaled nitric oxide, and ECMO were relatively low, pulmonary hypertension did not seem to explain this worse outcome for eventration patients of $\mathrm{CDH}$ patients with a hernia sac. Other explanations may be the presence of a more pronounced or underestimated pulmonary hypoplasia, a lesser functional diaphragm than previously thought (with higher recurrences) or the higher presence of other birth defects, which was shown in this study. Whatever the cause, the poor pulmonary condition with higher need for respiratory support at 30 days and at discharge warrants close pulmonary follow-up in this group of patients. In a future prospective study on this subject, it would be interesting to look for diaphragm motility disorder during follow-up, not only to explain difference in clinical follow-up but also to correct the outcomes for type of repair and its consequence on the function of the diaphragm. This could give us new insights in the type of surgery, type of defect, and functional outcome on the requirement of more ventilation and oxygen. Two previous studies by Levesque et al. (2019) and Oliver et al. (2019) showed a lower oxygen dependency after 28 respectively 30 days for hernia sac patients [28, 29]. However, all of these studies (including this study) are retrospective single center studies; therefore differences in diagnostics and treatment could give a bias (e.g., a difference in ECMO rate). Moreover, there may also be differences in the comparison to the patient groups of both centers in the non-hernia sac group, as, for example, in this study, eventration patients were excluded from the non-hernia sac group. Despite the differences between the patient groups, the rate of oxygen supply for hernia sac patients in our study seems to be comparable to the study by Oliver et al. (2019) (39\% versus 44\%). For the long-term follow-up, pulmonary function does seem to improve, as was also shown in other studies $[13,14,23]$. Wu et al. (2015) proved that the symptoms of their 86 symptomatic eventration patients resolved after surgery so timely diagnosis and treatment are related to lower respiratory morbidity (such as respiratory chest infection and cough) in these patients [19].

\section{Limitations}

Due to the retrospective nature, data collection was incomplete and may be less reliable. Examples were the lack of access to data from the prenatal period such as the observed lung-to-head ratio (O/E LHR). For example, patch repair had to be used as surrogate for the size of the defect. The pooling of the data in the combined $\mathrm{CDH}$ hernia sac group and eventration group for subanalysis of comparison between a true and non-true defect may hypothetically be right but may have given a bias as well, based on the relatively small sample sizes of especially hernia sac and eventration patients. Although no significant differences in characteristics and outcome of these patients were found, a larger prospective cohort needs to confirm that these groups can be seen as one and give definite conclusions of the data given in this study. Also, the fact that some of the patients did not survive, mainly in the true Bochdalek group, could give a bias in the long-term outcome; however this group was not the focus of this study.

\section{Conclusion}

The recurrence rate for patients without a true congenital diaphragmatic hernia defect (hernia sac and eventration) seems to be higher than for patients with a true Bochdalek type congenital diaphragmatic hernia. The similarities in these patients without a true defect found in this study can be an indication that these defects are often underestimated. The short-term outcomes of these patients are comparable to patients with a small true diaphragmatic defect, while the long-term prognosis is more comparable to patients with a large defect. Further studies are needed to evaluate whether the surgical techniques (to use or patch or not) for these specific defects need to be adjusted to prevent recurrences and improve the pulmonary outcome at 30 days of age and at discharge.

Authors' contribution K. Heiwegen and M. van Peperstraten were responsible for data collection and drafted the initial manuscript. K. Heiwegen revised data analyses and made the final manuscript, as submitted. S. Botden was responsible for study design, methodology, supervision of analysis, and oversight of the study. I.de Blaauw, A. van Heijst and $\mathrm{H}$. Scharbatke were responsible for investigation, supervision, and reviewing the manuscript and approved the final manuscript.

\section{Compliance with ethical statements}

Conflict of interest The authors declare that they have no conflict of interest.

Ethical approval This article does not contain any studies with human participants or animals performed by any of the authors. This study was approved by the local medical ethical committee, and all data was processed anonymously, according to the privacy legislation. 
Open Access This article is licensed under a Creative Commons Attribution 4.0 International License, which permits use, sharing, adaptation, distribution and reproduction in any medium or format, as long as you give appropriate credit to the original author(s) and the source, provide a link to the Creative Commons licence, and indicate if changes were made. The images or other third party material in this article are included in the article's Creative Commons licence, unless indicated otherwise in a credit line to the material. If material is not included in the article's Creative Commons licence and your intended use is not permitted by statutory regulation or exceeds the permitted use, you will need to obtain permission directly from the copyright holder. To view a copy of this licence, visit http://creativecommons.org/licenses/by/4.0/.

\section{References}

1. Leeuwen L, Fitzgerald DA (2014) Congenital diaphragmatic hernia. J Paediatr Child Health 50:667-673

2. Kays DW, Islam S, Larson SD, Perkins J, Talbert JL (2013) Longterm maturation of congenital diaphragmatic hernia treatment results: toward development of a severity-specific treatment algorithm. Ann Surg 258:638-644 discussion 644-635

3. Pober BR, Russell MK, Ackerman KG (2006) Congenital diaphragmatic hernia overview. In: Pagon RA, Adam MP, Ardinger $\mathrm{HH}$ et al (eds) gene reviews

4. Clugston RD, Greer JJ (2007) Diaphragm development and congenital diaphragmatic hernia. Semin Pediatr Surg 16:94-100

5. Harting MT, Lally KP (2014) The congenital diaphragmatic hernia study group registry update. Sem Fetal Neonatal Med 19:370-375

6. Tsao K, Lally KP (2008) The congenital diaphragmatic hernia study group: a voluntary international registry. Semin Pediatr Surg 17:90-97

7. Yazici M, Karaca I, Arikan A, Erikci V, Etensel B, Temir G, Sencan A, Ural Z, MutafO (2003) Congenital eventration of the diaphragm in children: 25 years' experience in three pediatric surgery centers. Eur J Pediatr Surg 13:298-301

8. Puligandla PS, Grabowski J, Austin M, Hedrick H, Renaud E, Arnold M, Williams RF, Graziano K, Dasgupta R, McKee M, Lopez ME, Jancelewicz T, Goldin A, Downard CD, Islam S (2015) Management of congenital diaphragmatic hernia: a systematic review from the APSA outcomes and evidence based practice committee. J Pediatr Surg 50:1958-1970

9. Zani A, Zani-Ruttenstock E, Pierro A (2014) Advances in the surgical approach to congenital diaphragmatic hernia. Semin Fetal Neonatal Med 19:364-369

10. Hollinger LE, Lally PA, Tsao K, Wray CJ, Lally KP (2014) A riskstratified analysis of delayed congenital diaphragmatic hernia repair: does timing of operation matter? Surgery 156:475-482

11. Fallon SC, Cass DL, Olutoye OO, Zamora IJ, Lazar DA, Larimer EL, Welty SE, Moise AA, Demny AB, Lee TC (2013) Repair of congenital diaphragmatic hernias on extracorporeal membrane oxygenation (ECMO): does early repair improve patient survival? J Pediatr Surg 48:1172-1176

12. Congenital Diaphragmatic Hernia Study G, Lally KP, Lally PA, Lasky RE, Tibboel D, Jaksic T, Wilson JM, Frenckner B, Van Meurs KP, Bohn DJ, Davis CF, Hirschl RB (2007) Defect size determines survival in infants with congenital diaphragmatic hernia. Pediatrics 120:e651-e657

13. Spaggiari E, Stirnemann J, Bernard JP, De Saint BL, Beaudoin S, Ville Y (2013) Prognostic value of a hernia sac in congenital diaphragmatic hernia. Ultrasound Obst Gyn 41:286-290
14. Panda SS, Bajpai M, Srinivas M (2013) Presence of hernia sac in prediction of postoperative outcome in congenital diaphragmatic hernia. Indian Pediatr 50:1041-1043

15. Morini F, Valfre L, Capolupo I, Lally KP, Lally PA, Bagolan P (2013) Congenital diaphragmatic hernia: defect size correlates with developmental defect. J Pediatr Surg 48:1177-1182

16. Lally KP, Lasky RE, Lally PA, Bagolan P, Davis CF, Frenckner BP, Hirschl RM, Langham MR, Buchmiller TL, Usui N, Tibboel D, Wilson JM, Congenital Diaphragmatic Hernia Study G (2013) Standardized reporting for congenital diaphragmatic hernia-an international consensus. J Pediatr Surg 48:2408-2415

17. Reiss I, Schaible T, van den Hout L, Capolupo I, Allegaert K, van Heijst A, Gorett Silva M, Greenough A, Tibboel D (2010) Standardized postnatal management of infants with congenital diaphragmatic hernia in Europe: the CDH EURO consortium consensus. Neonatology 98:354-364

18. Veenma DCM, de Klein A, Tibboel D (2012) Developmental and genetic aspects of congenital diaphragmatic hernia. Pediatr Pulmonol 47:534-545

19. Wu S, Zang N, Zhu J, Pan Z, Wu C (2015) Congenital diaphragmatic eventration in children: 12 years' experience with 177 cases in a single institution. J Pediatr Surg 50:1088-1092

20. Tsugawa C, Kimura K, Nishijima E, Muraji T, Yamaguchi M (1997) Diaphragmatic eventration in infants and children: is conservative treatment justified? J Pediatr Surg 32:1643-1644

21. Ghribi A, Bouden A, Braiki M, Jabloun A, Sghairoun N, Gasmi M, Hamzaoui M (2015) Diaphragmatic eventration in children. Tunis Med 93:76-78

22. $\mathrm{Hu}$ J, Wu Y, Wang J, Zhang C, Pan W, Zhou Y (2014) Thoracoscopic and laparoscopic plication of the hemidiaphragm is effective in the management of diaphragmatic eventration. Pediatr Surg Int 30:19-24

23. Zamora IJ, Cass DL, Lee TC, Welty S, Cassady CI, Mehollin-Ray AR, Fallon SC, Ruano R, Belfort MA, Olutoye OO (2013) The presence of a hernia sac in congenital diaphragmatic hernia is associated with better fetal lung growth and outcomes. J Pediatr Surg 48:1165-1171

24. Putnam LR, Gupta V, Tsao K, Davis CF, Lally PA, Lally KP, Harting MT (2017) Factors associated with early recurrence after congenital diaphragmatic hernia repair. J Pediatr Surg

25. Janssen S, Heiwegen K, van Rooij IA, Scharbatke H, Roukema J, de Blaauw I, Botden SM (2017) Factors related to long-term surgical morbidity in congenital diaphragmatic hernia survivors. J Pediatr Surg

26. Heiwegen K, De Blaauw I, Janssen S, van Rooij IA, van Heijst A, Botden SM (2017) Short term surgical outcomes in the treatment of congenital diaphragmatic hernia: an overview of 15 years' experience. Ann Emerg Surg 2:1005

27. Putnam LR, Tsao K, Lally KP, Blakely ML, Jancelewicz T, Lally PA, Harting MT (2017) Minimally invasive vs open congenital diaphragmatic hernia repair: is there a superior approach? J Am Coll Surg 224:416-422

28. Levesque M, Derraugh G, Schantz D, Morris MI, Shawyer A, Lum Min SA, Keijzer R (2019) The presence of a hernia sac in isolated congenital diaphragmatic hernia is associated with less disease severity: a retrospective cohort study. J Pediatr Surg

29. Oliver ER, DeBari SE, Adams SE, Didier RA, Horii SC, Victoria T, Hedrick HL, Adzick NS, Howell LJ, Moldenhauer JS, Coleman BG (2019) Congenital diaphragmatic hernia sacs: prenatal imaging and associated postnatal outcomes. Pediatr Radiol 49:593-599

Publisher's note Springer Nature remains neutral with regard to jurisdictional claims in published maps and institutional affiliations. 